\title{
Evidence for the presence of lactoferrin in odontogenic keratocyst fluids
}

\author{
C W I DOUGLAS, G T CRAIG \\ From the Department of Oral Pathology, University of Sheffield
}

SUMMARY Investigations into the possibility that $\mathrm{X}$ (an antigen consistently present in aspirate odontogenic keratocysts, but not in most fluids from other cyst types), represented a keratinocytte् component failed to identify the antigen as a keratin, involucrin, or one of the blood group sub stances. Antigen $\mathrm{X}$ was detected in human mixed and parotid saliva and in colostrum, as well as in a commercially obtained preparation of colostral IgA. The antigen was similar biochemically tog both secretory component and lactoferrin but proved to be identical antigenically with lactoferrin-

The origin of lactoferrin in keratocyst fluids remains uncertain, though the lining epithelium? seems a more likely source than does the very variable, and often negligible, inflammatory infiltrate found in these lesions.

Of the cysts that occur in the jaws, only the odontogenic keratocyst shows a significant tendency to recur after surgical removal. ${ }^{1}$ Since a proportion of coventionally biopsied cystic tissue cannot be diagnosed histologically, usually because of excessive inflammation, other methods of achieving accurate preoperative diagnosis have been investigated. Toller examined the total soluble protein concentrations in the fluid that can usually be aspirated from these cysts and showed that keratocyst fluids contained a significantly lower concentration of protein. ${ }^{2}$ This characteristic, along with the presence of keratinised squames in the fluid, ${ }^{3}$ is held to be consistent with a diagnosis of odontogenic keratocyst.

Nevertheless, as some cysts are often heavily inflamed or infected and fluid aspirates commonly become contaminated with blood during collection, the total protein concentration tends to be raised. Clearly, then, protein concentration alone cannot be relied on for diagnosis, and recognition of more definitive markers in cyst fluids would be advantageous. We recently described a study in which a range of cyst fluids was analysed immunochemically in an attempt to identify markers specific to odontogenic keratocysts. ${ }^{45}$ By raising an antiserum against pooled keratocyst fluids and screening individual cyst fluids against this serum, an antigen, designated $\mathrm{X}$, was identified that seemed to be confined to keratocyst fluids. The presence and detection of $X$ was independent of the concentration of total soluble

Accepted for publication 26 March 1987 protein and did not seem to be related to the presencev or degree of inflammation.

Antigen $\mathrm{X}$ was not detected in serum, and somes evidence suggested that it might originate from the epithelium lining the cyst cavity. Antigen $X$ was shown to be distinct from most human keratins, ${ }^{5}$ and so the present study investigated a variety of other substances associated with epithelium as potentia? candidates for identification with $\mathbf{X}$. These included involucrin, ${ }^{6}$ blood group substances, ${ }^{7}$ and the secre tory substances lactoferrin ${ }^{8}$ and secretory com ponent. ${ }^{9}$ We report here evidence to indicate thaf antigen $X$ can be identified as lactoferrin.

\section{Material and methods}

CYST FLUIDS

A variety of fluids that had been aspirated from cystio lesions diagnosed histologically as odontogenic kera으․ tocysts were used as the source of antigen $\mathrm{X}$. These keratocyst fluids had been collected over a period of six years and stored at $-20^{\circ} \mathrm{C}$. The total soluble pro 0 tein concentration of the fluids ranged from 1.8-10 $\mathrm{g} / 100 \mathrm{ml}$ and prior to use fluids were centrifuged ato $11600 \mathrm{~g}$ for 10 minutes in an MSE microcentaur ceno trifuge.

SALIVA AND COLOSTRUM

Human whole mixed saliva (from the authors) wa옹 stimulated by chewing parafilm (American Can Co.\$ and cleared by centrifugation at $11600 \mathrm{~g}$ for $1 \Phi$ minutes in an MSE microcentaur centrifuge. Paroti尔 
saliva was collected from the authors using a CarlsonCrittenden cup while stimulating the tongue with lemon oil.

Pooled human colostrum collected in the period immediately after birth was obtained from the University department of obstetrics and gynaecology, Sheffield.

\section{ANTISERA}

Antibodies to a partially purified preparation of antigen $X$ and to human whole mixed saliva were raised in New Zealand white rabbits by three consecutive injections at three weekly intervals, using aluminium hydroxide as adjuvant (Alu Gel S, Serva, Heidelberg). The IgG fractions of the resultant antisera were then prepared according to the method of Steinbuch and Audran. ${ }^{10}$

Antiserum to involucrin was a kind gift from $\mathrm{Dr} \mathbf{J}$ Davies, University department of pathology, Bristol, and antisera to human blood group antigens $\mathrm{A}, \mathrm{B}, \mathrm{O}$, Lewis $a$, Lewis $b$, and $p$ were donated by the Regional Blood Transfusion Service, Sheffield. Antihuman lactoferrin immunoglobulin, antisecretory component antibody, and antibody to human serum constituents were obtained from Dakopatts Ltd (Denmark). Anti$\alpha$ chain serum was obtained from Boehringer (Mannheim).

\section{PARTIAL PURIFICATION OF ANTIGEN X}

Ten keratocyst fluids were pooled and chromatographed on a column (total volume $75 \mathrm{ml}$ ) of Sepharose CL-6B (Pharmacia, Sweden), equilibrated, and eluted with $0.05 \mathrm{M}$ phosphate buffer at $\mathrm{pH} 7.0$ and containing $0.1 \%$ sodium azide. Fractions $(1 \mathrm{ml})$ were collected and $10 \mu$ portions electrophoresed by the method of Weeke ${ }^{11}$ into $1 \%$ agarose containing antikeratocyst fluid serum through an intermediate gel containing antihuman serum antibody.

Antigen $\mathrm{X}$ began to emerge from the column shortly after the void volume (fraction 6), peaked in fraction 17, and persisted until fraction 22 . The bulk of the serum related components began to elute in fraction 12; accordingly, fractions 6-11 were pooled and used to raise an antiserum against antigen $X{ }^{5}$

The anti-X serum obtained was then coupled to a silica matrix activated with glutaraldehyde $(B C L$, London) and packed into a column $(10 \times 1 \mathrm{~cm})$. An antihuman serum immunoaffinity column was also prepared by coupling commercial antihuman serum immunoglobulin to the same affinity matrix. All subsequent preparations of antigen $\mathrm{X}$ were produced by initial passage of a mixture of keratocyst fluids through the anti-X immunoaffinity column followed by washing and desorption with $10 \mathrm{mM}$ hydrochloric acid. This "enriched" $X$ preparation contained some contaminant serum components. After dialysis against $0.05 \mathrm{M}$ phosphate buffer the serum contaminants were removed by passage through the antihuman serum affinity column. The resultant partially purified antigen $\mathbf{X}$ material was almost totally devoid of most contaminant material, as judged by probing Western blots with antihuman serum and antikeratin antibodies.

SODIUM DODECYL SULPHATE-POLYACRYLAMIDE GEL ELECTROPHORESIS (SDS-PAGE) AND

WESTERN BLOTTING

Samples were electrophoresed in the presence of SDS on $9 \%$ polyacrylamide gels according to the method described by Russell, ${ }^{12}$ but with the exception that $\beta$-mercaptoethanol was usually omitted from the sample buffer.

Electrophoretic transfer of proteins on to nitrocellulose (Schleicher and Schull, Dassel, West Germany) following SDS-PAGE - that is, Western blotting - was performed essentially according to the method of Burnette, ${ }^{13}$ but with the modifications reported by Douglas and Russell. ${ }^{14}$

\section{CROSSED IMMUNOELECTROPHORESIS (CIE)}

CIE was performed according to the method of Eckersall and Beeley, ${ }^{15}$ but with an intermediate gel containing a relevant antiserum. Samples of keratocyst fluids were diluted $1 / 10$ in water for use.

In some experiments keratocyst fluids were examined by running in "tandem" with human lactoferrin in the CIE system.

\section{IMMUNOAFFINITY CHROMATOGRAPHY OF} SECRETORY IgA (S-IgA)

A commercial preparation of colostral S-IgA (Sigma) was passed down an immunoaffinity column constructed from anti- $\alpha$ chain antibodies (Boehringer, Mannheim) and antisecretory component immunoglobulin (Dako) immobilised on a matrix activated with glutaraldehyde (BCL, London). Bound constituents were desorbed using $10 \mathrm{mM}$ hydrochloric acid and, after dialysis, both the bound and non-bound components were examined by western blotting.

\section{PREPARATION OF COLOSTRAL FREE SECRETORY COMPONENT}

Colostral free secretory component was prepared according to the method of Mach. ${ }^{16}$

\section{BINDING ASSAYS}

Dimeric IgA (d-IgA) was purified from dog serum using DEAE-ion exchange and gel filtration chromatography, as described by Putnam et al. ${ }^{17}$ Doubling dilutions of dimeric $\operatorname{IgA}$ were allowed to bind in a series of ELISA tray wells at pH 9.0 and excess dimeric IgA then washed away. A standard dilution 
of secretory component or antigen $\mathrm{X}$ preparation was then allowed to interact with the immobilised d-IgA in $0.14 \mathrm{M} \mathrm{NaCl}$, adjusted to $\mathrm{pH} 7.4$ with $0.01 \mathrm{M}$ phosphate buffer according to the method of Mach. ${ }^{16}$ After washing bound secretory component or antigen $\mathrm{X}$ were detected with specific antibody followe by peroxidase conjugated second antibody (Sigma). The peroxidase substrate used was o-phenylenediamine $(400 \mu \mathrm{g} / \mathrm{ml})$ in citrate phosphate buffer $(0.02 \mathrm{M}, \mathrm{pH}$ $5 \cdot 0)$.

\section{IMMUNOHISTOCHEMISTR Y}

Anti-X antibody and anti-secretory component antibody probed sections of formalin fixed, paraffin

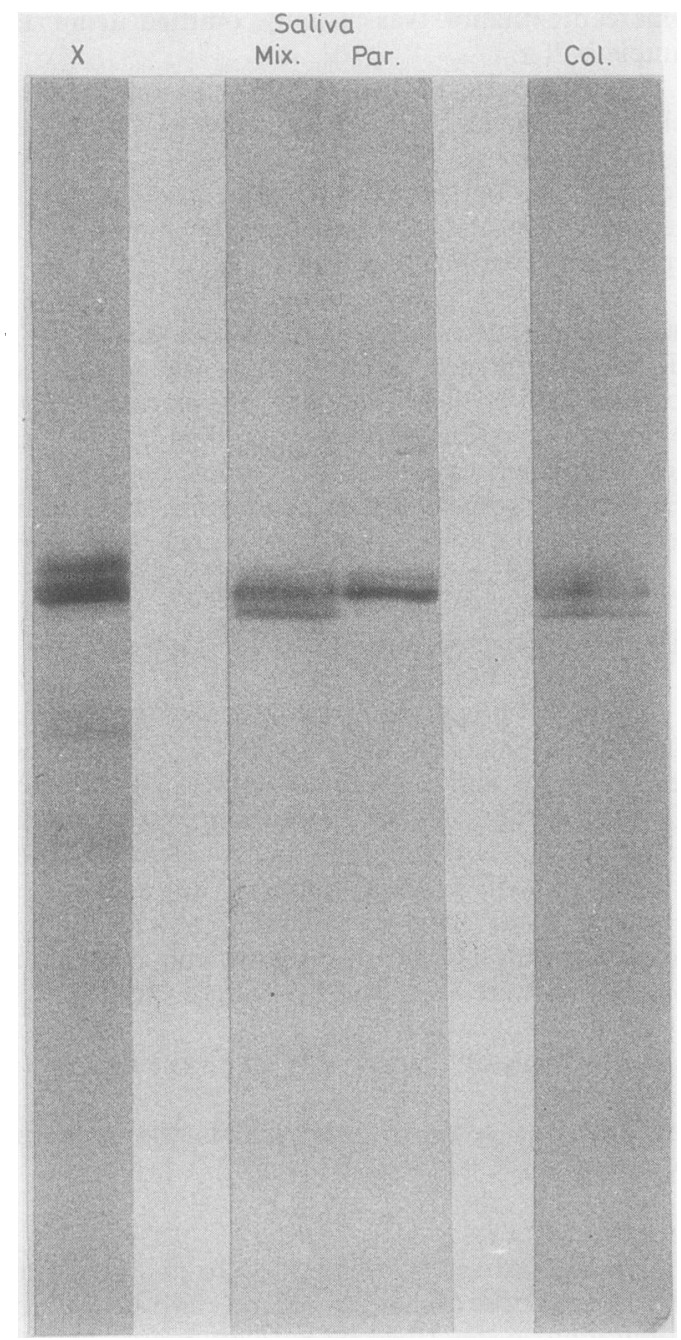

Fig 1 Western blots of antigen $X$, human mixed and parotid saliva, and human colostrum separated by $9 \%$ SDS$P A G E$ and probed with anti-X serum. embedded, parotid salivary gland tissue were processed using the peroxidase-antiperoxidase method $\underline{\underline{\sigma}}$ outlined by Mepham, Fraser, and Mitchell. ${ }^{18}$ Sections were treated with $0.05 \%$ trypsin (Sigma) in $\stackrel{9}{+}$ $0.1 \% \mathrm{CaCl}_{2}$ adjusted to $\mathrm{pH} 7.8$ with $0.1 \mathrm{~N} \mathrm{NaOH}$ for 20 minutes at $37^{\circ} \mathrm{C}$.

\section{Results}

IDENTITY OF X: INVOLUCRIN OR BLOOD GROUP ANTIGENS?

In Western blots none of the antisera used recognised $\overrightarrow{\vec{\omega}}$ antigen X (data not shown).

\section{DISTRIBUTION OF ANTIGEN $X$}

Fig 1 shows the assay for the presence of antigen $X$ in ${ }_{\infty}^{\circ}$ whole mixed and parotid saliva and in colostrum by $\dot{0}$ Western blotting. The antigen was readily identified $\vec{A}$ in all these secretions and, although not measured, the 의 amount of $\mathrm{X}$ present in each was considerable, partic- ularly in colostrum as the sample had to be diluted $1 / 300$ to avoid overloading of the gel. Some variation in the band patterns of antigen $X$ was observed $\stackrel{\oplus}{\oplus}$ between the various samples but the reason for this is $\overrightarrow{0}$

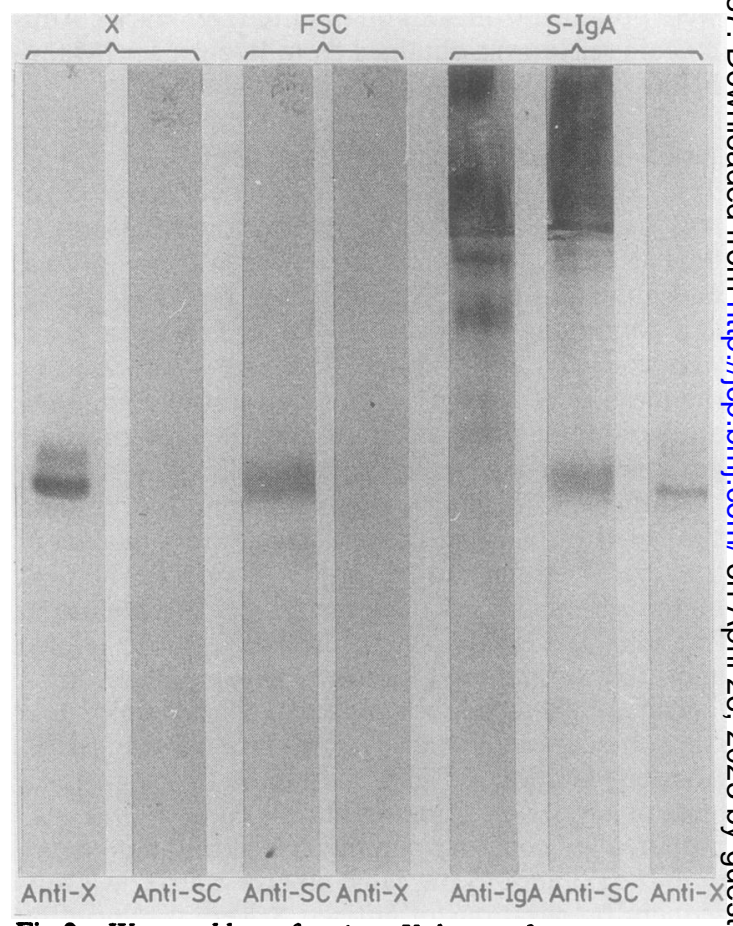

Fig 2 Western blots of antigen $X$, human free secretory component (FSC) and human secretory $\operatorname{Ig} A(S-\operatorname{Ig} A)$ separated by $9 \%$ SDS-PAGE and each probed with anti-X serum and antiserum to free secretory component (anti-SC) $S$-IgA was also probed with antiserum to $\alpha$-chain (antiIgA).

-


not known at present.

Bearing the above results in mind, along with the previously reported biochemical characteristics of antigen $\mathrm{X}^{5}$ and the fact that it is not of serum origin or of the keratin family, we speculated at this stage that $\mathrm{X}$ might be secretory component.

IDENTITY OF X: SECRETORY COMPONENT

Using the method of Western blotting, antibody to antigen $\mathrm{X}$ did not recognise secretory component isolated from human colostrum (fig 2), nor did antibody to free secretory component recognise antigen $\mathrm{X}$. Anti-X antibody did, however, recognise a molecule running to the same position as secretory component when a preparation of colostral secretory IgA was run in dissociating conditions and probed on Western blots (fig 2). At no time did anti- $\alpha$ chain serum recognise antigen $X$ and anti- $X$ serum did not recognise IgA.

\section{S-IgA PURIFICATION BY IMMUNOAFFINITY}

\section{CHROMATOGRAPHY}

To investigate further the apparent anomolous observation that a component in the S-IgA preparation was similar antigenically to $\mathrm{X}$, attempts were made to separate any unbound impurities from either $S-\operatorname{IgA}$ or any free secretory component that may have been present. An affinity column, constructed from anti $\alpha$-chain and antisecretory component immunoglobulins, was used, and the material passing straight through the column, and that bound and subsequently desorbed, were assayed by Western blotting. No material recognisable by anti-X antibody passed straight through the affinity column. All the "anti-X-positive" material remained bound to the column; after desorption with $10 \mathrm{mM}$ hydrochloric acid this component ran to a position corresponding to that of secretory component on SDS-PAGE.

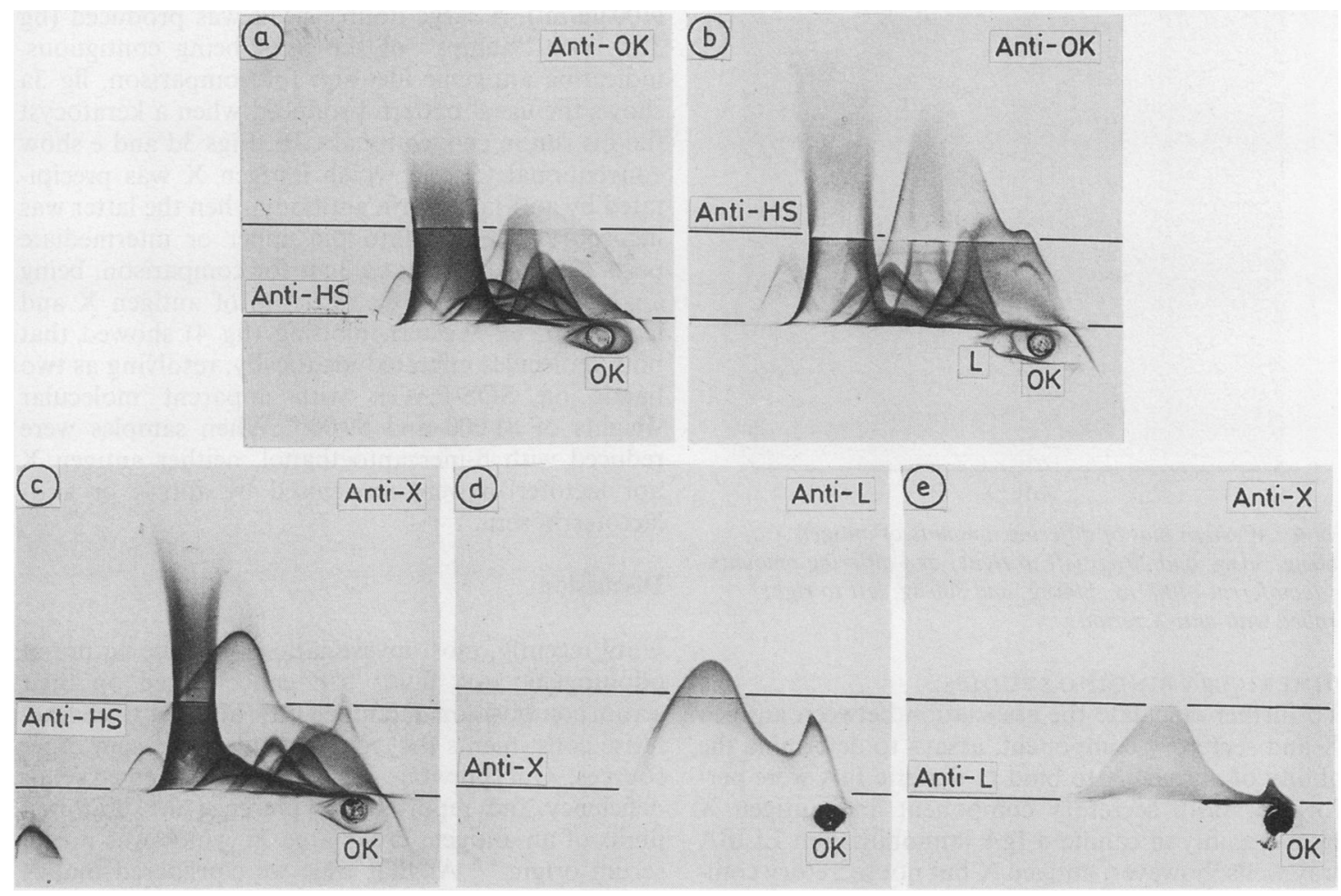

Fig 3 (a) Keratocyst fluid (OK) analysed by crossed immunoelectrophoresis into antikeratocyst fluid serum (anti-OK) through intermediate gel containing antihuman serum (anti-HS); (b) tandem crossed immunoelectrophoresis of keratocyst fluid $(O K)$ used in $(a)$ and lactoferrin $(L)$ into antikeratocyst fluid serum through an antihuman serum intermediate gel. Antigen $X$ and lactoferrin peaks fuse indicating that they are similar antigenically; (c) crossed immunoelectrophoresis of keratocyst fluid into anti-X serum through antihuman serum intermediate gel. (d) Crossed immunoelectrophoresis of keratocyst fluid used in (c) into anti-lactoferrin serum (anti- $L$ ) through intermediate gel containing anti-X serum. (e) Crossed immunoelectrophoresis of keratocyst fluid used in (c) into anti-X serum through intermediate gel containing anti-lactoferrin serum. 


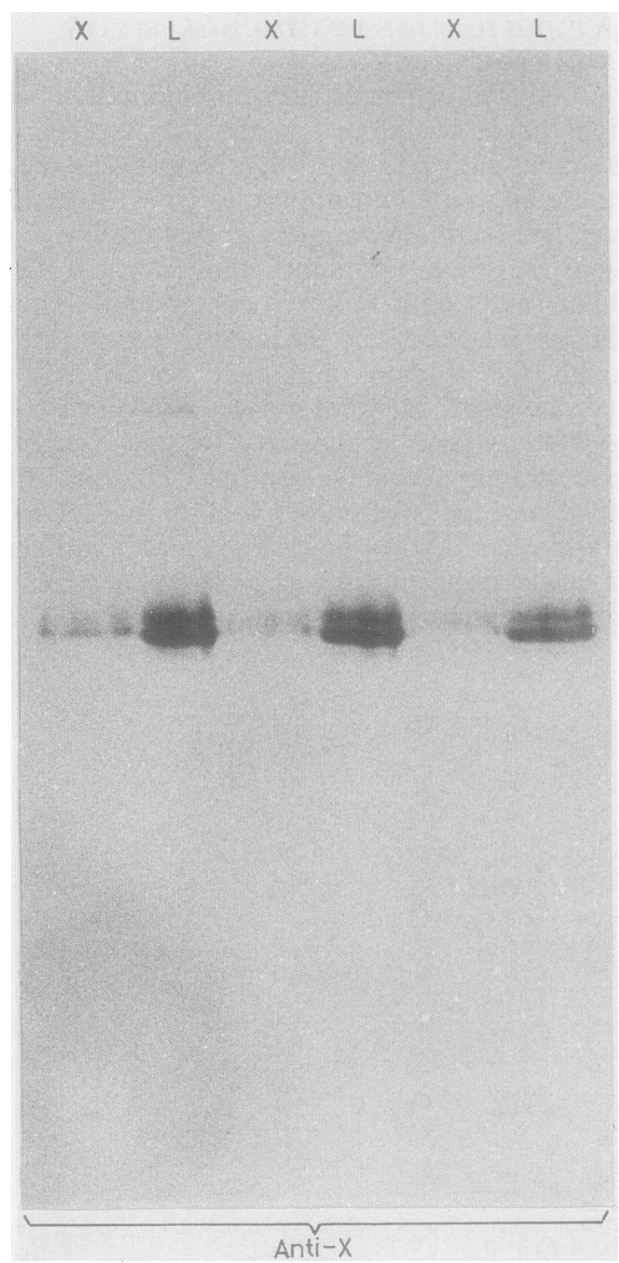

Fig 4 Western blot of differing amounts of antigen $X$ $(60 \mathrm{ng}, 30 \mathrm{ng}$, and $20 \mathrm{ng}$, left to right) and differing amounts of lactoferrin (1000 ng, $800 \mathrm{ng}$, and $300 \mathrm{ng}$, left to right) probed with anti-X serum.

\section{DIMERIC-IgA BINDING STUDIES}

To further elucidate the association between antigen $\mathrm{X}$ and secretory component, assays to determine the ability of antigen $X$ to bind to dimeric IgA were performed. Both secretory component and antigen $X$ bound avidly to canine d-IgA immobilised in ELISA tray wells; however, antigen $\mathrm{X}$ but not secretory component, also bound to bovine serum albumin included as a control.

\section{IMMUNOHISTOCHEMICAL LOCALISATION OF} ANTIGEN X IN SALIVARY GLAND TISSUE

Attempts were made to determine the location of antigen $X$ in tissue from which $X$ is known to derive, and to compare this with the location of secretory component in the same tissue. Parotid salivary gland tissue was therefore used and immunoperoxidase screening showed strong positive staining of both acinar and ductal cells with the antisecretory component $\overrightarrow{\vec{s}}$ serum, but only weak staining with anti-X antibody. $\overrightarrow{0}$ Antiserum to $X$, however, did stain the cytoplasm of $\frac{C}{0}$ infiltrating polymorphonuclear leucocytes (PMNL) $\frac{\bar{p}}{\overline{2}}$ very strongly, and this was not attributable to endo- $\mathbb{D}$ genous peroxidase activity in these cells, as control sections not treated with primary antibody failed to क show any positive staining (data not shown).

IDENTITY OF X: LACTOFERRIN?

Since anti-X antibodies stained PMNL strongly by the immunoperoxidase method we investigated the possibility that $\mathrm{X}$ might be lactoferrin, a substance present in both PMNL and body secretions but not in serum. This thesis was initially tested using "tandem" $\vec{A}$ crossed immunoelectrophoresis in which a keratocyst 0 fluid was run alongside a sample of lactoferrin $(100 \mu \mathrm{g} / \mathrm{ml})$. A large double peak was produced (fig $\longrightarrow$ $3 \mathrm{~b})$, both "humps" of the peak being contiguous, indicating antigenic identity; for comparison, fig 3a की shows the usual pattern produced when a keratocyst $\vec{A}$ fluid is run in conventional CIE. Figs $3 \mathrm{~d}$ and e show $\infty$ conventional CIE in which antigen $X$ was precipitated by anti-lactoferrin antibody when the latter was incorporated either into the upper or intermediate parts of the gel; again fig $3 \mathrm{c}$ is for comparison, being analogous to fig 3a. Comparison of antigen $X$ and $\stackrel{2}{\varnothing}$ lactoferrin by Western blotting (fig 4) showed that $\stackrel{\unrhd}{\unrhd}$ both molecules migrated identically, resolving as two $\vec{\overrightarrow{ }}$ bands on SDS-PAGE with apparent molecular 3 weights of 81000 and 89000 . When samples were reduced with $\beta$-mercaptoethanol, neither antigen $X$ nor lactoferrin were recognised by anti-X or antilactoferrin sera.

\section{Discussion}

Until recently, most investigations into the nature of

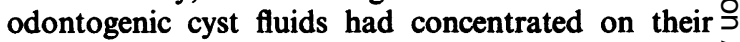
serum composition and made little attempt to charac- $\frac{D}{O}$ terise constituents that may have derived from other sources. Our previous study aimed to remedy this $N$ deficiency and reported the presence in keratocyst ${ }_{N}$ fluids of an antigen, designated $\mathrm{X}$, which was not of $O$ serum origin. ${ }^{45}$ At that time we considered that $X \mathrm{~W}$ could be derived from the epithelial lining of the cyst but was unlikely to be a 'universal' epithelial component as the antigen had not been found in fluids $\Phi$ from either radicular or dentigerous cysts, which are ${ }_{-}^{+}$ also lined by odontogenic epithelium, albeit of sim- $\frac{T}{0}$ pler configuration and exhibiting lower intrinsic $\stackrel{\odot}{\mathbb{D}}$

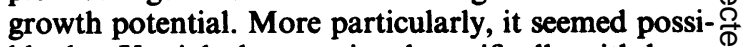
ble that $\mathrm{X}$ might be associated specifically with kera- $\stackrel{\mathbb{Q}}{2}$ 
tinising epithelia, although we recently reported that $\mathrm{X}$ was distinct from most cornification keratins. ${ }^{5}$ Another substance that is exclusively associated with keratinocytes and was, therefore, thought worthy of consideration, is involucrin, a cytoplasmic protein that has a role, along with several other membrane associated proteins, in the formation of an insoluble submembranous envelope during differentiation. ${ }^{6} 19$ Involucrin was originally reported as having an apparent molecular weight of $90000,^{6}$ but more recently it has been shown to behave anomolously in PAGE depending on the polyacrylamide concentration used. ${ }^{19}$ Accordingly, we considered that involucrin might well behave in a manner similar to that of antigen $\mathrm{X}$, which resolves as two bands with molecular weights of 81000 and 89000 in the SDSPAGE system used here. By Western blotting, however, $\mathrm{X}$ was shown to be antigenically distinct from involucrin. Thus although no specific association between antigen $\mathrm{X}$ and keratinocyte components could be found, it still seemed unlikely that $X$ was a general epithelial component, although at this stage it was not known if the antigen was present in other lesions, body sites, or fluids. We therefore assayed certain secretions for the presence of antigen $\mathbf{X}$ and found easily detectable quantities in mixed and parotid salivas, and in colostrum; these findings led us to consider which components might be common to both epithelial secretions.

Of the various possibilities, two substances in particular seemed to have similar biochemical properties to antigen X-namely, secretory component and lactoferrin. Blood group antigens were also considered at this juncture because of their known association with epithelial membranes, but these proved to be unrelated to $X$ antigenically.

Secretory component is an epithelial product responsible for the transport of dimeric IgA across the epithelial barrier ${ }^{9}$ and reportedly has molecular weights in the range 78000 to 90000 . It resolves as a double band on SDS-PAGE ${ }^{20}$ and has a major antigenic epitope that is sensitive to reduction with $\beta$-mercaptoethanol. ${ }^{21}$ Lactoferrin is an iron binding protein that is both actively released into external secretions $^{22}$ and is also present in the azurophilic granules of polymorphonuclear leucocytes $(\mathrm{PMNL})^{23}$; its reported molecular weight is in the range 76800-85000. ${ }^{24} 25$ Although the molecule comprises two iron binding sites stabilised by disulphide bonds, ${ }^{26}$ we are not aware of any reports indicating that the major antigenic epitope of the molecule spans these sites, thus making it sensitive to reduction with $\beta$-mercaptoethanol. In this regard it seemed that antigen $X$ showed a greater similarity to secretory component and, therefore, their association was investigated first.
Western blot analysis of free secretory component showed that it was not recognised by anti- $X$ antibody, nor did antibody directed against the free or bound forms of secretory component recognise antigen $X$. Interestingly, however, anti-X serum did recognise a component in a commercial preparation of S-IgA which migrated to the same position as secretory component in SDS-PAGE. This "X-positive" material was not a fragment of IgA as it was not recognised by anti- $\alpha$ chain antibody and anti-X serum did not recognise IgA. Could the "X-positive" material be an unusual form of secretory component? Although reducing conditions are normally considered to be necessary to cleave secretory component from S-IgA, ${ }^{27}$ some did seem to be released by boiling in SDS in the absence of $\beta$-mercaptoethanol, or possibly some free secretory component was also present in the S-IgA preparation we used here. An alternative interpretation for the presence of "X-positive" material in the S-IgA preparation is that it merely represents an unrelated contaminant that fortuitously has a molecular weight similar to secretory component.

To try to resolve these two possible explanations we first attempted to separate any contaminants from any free secretory component that might have been present and from the S-IgA, by chromatography on an affinity column constructed from anti- $\alpha$ chain and anti-secretory component immunoglobulins. The material recognised by anti-X serum bound to the column and subsequently was desorbed along with S-IgA, again suggesting that it might be related to secretory component.

Investigations into the biological activity of secretory component and antigen $\mathrm{X}$, however, showed that like secretory component ${ }^{16} \mathrm{X}$ was capable of binding to dog dimeric IgA; in contrast to secretory component, however, antigen $\mathrm{X}$ also bound to bovine serum albumin which had been included as a control. Such non-specific binding to proteins other than dimeric $\operatorname{IgA}$ or pentameric IgM has not been reported for secretory component, ${ }^{16}$ but the other candidate substance under consideration for identity with $\mathrm{X}$ namely lactoferrin-is known to interact with a variety of proteins. ${ }^{28}$

Although some of the data discussed so far tend to suggest that antigen $\mathrm{X}$ is an unusual form of secretory component, there are important differences between them, not least being the lack of recognition of $X$ by antisecretory component sera. Furthermore, should $\mathrm{X}$ be a variant form of secretory component, one might expect that it would share at least some antigenic epitopes with the native form of the molecule. Therefore the 'X-positive' material in our S-IgA preparation, which comigrates with secretory component on SDS-PAGE, is more likely to be an impurity than a variant secretory component, and the fact that this 
material was retained on the anti- $\alpha$ chain immunoaffinity column could simply be explained on the basis of a strong, non-specific interaction between $X$ and IgA. Indeed, information obtained subsequently from the manufacturers of the S-IgA preparation used here has indicated that lactoferrin was present as an impurity to a level of $0.5 \%$.

The weight of evidence would now suggest that antigen $X$ is lactoferrin; this conclusion is supported by positive cytoplasmic staining of PMNL in tissue sections with anti-X antibody, specific interaction between lactoferrin, and anti-X antibody, in CIE and Western blots, and by anti-lactoferrin serum recognising antigen $X$. Chance antigenic cross reactivity between the two molecules, however, cannot be totally ruled out at this stage, even though the behaviour of $\mathrm{X}$ and lactoferrin seem to be identical on SDSPAGE.

Finally, the question arises as to how lactoferrin consistently accumulates in keratocyst fluids? Certainly, its presence would seem to be unrelated solely to inflammation as keratocysts, which have a developmental pathogenesis, are in most instances virtually uninflamed histologically at the time of diagnosis. In contrast, very few fluids from radicular cysts have been found to contain antigen $\mathrm{X}$, yet inflammation is an essential prerequisite in their pathogenesis. It is tempting to speculate, therefore, that in keratocyst fluids $\mathrm{X}$ originates from the epithelial lining rather than from infiltrating PMNL. Though lactoferrin is well characterised as a product of secretory epithelia - for example, breast, sweat gland, salivary gland-and in certain lining epithelia-gastric mucous neck cells and duodenum - a recent study failed to detect it in keratinising epithelium of skin. ${ }^{8}$ Nevertheless, both the major and minor salivary glands and the odontogenic epithelial remnants from which keratocysts are thought to arise share a common origin embryologically in the ectoderm that lines the primitive oral cavity; this suggests that keratocyst lining epithelium might exhibit a capacity for lactoferrin production. To date, however, our limited attempts at immunoperoxidase localisation of lactoferrin in formalin fixed keratocyst linings have been disappointing, though work in progress using different fixation schedules may help to resolve this problem.

An alternative explanation, however, for the presence of a relatively large amount of lactoferrin in keratocyst fluids might be related to the nature of the cyst lining, rather than to specific products of that lining. In view of the postulation that keratocyst linings are relatively impermeable to proteins ${ }^{29}$ it is possible that the PMNL that do infiltrate the cyst lining act as the source of lactoferrin in the cyst fluid. The lactoferrin concentration might, then, gradually increase with time, because it is unable to diffuse away $\stackrel{0}{5}$ into the surrounding tissues. Further work is required 은 to resolve these speculations.

We thank Professor CJ Smith for his constructive criticism of the manuscript, and Mr D Thompson for assistance with the photographic illustrations.

\section{References}

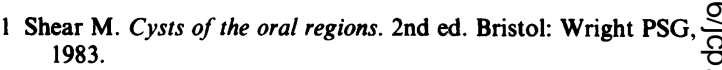

2 Toller PA. Origin and growth of cysts of the jaws. Ann $R$ Coll + Surg Engl 1967;40:306-36.

3 Kramer IRH, Toller PA. The use of exfoliative cytology and protein estimations in preoperative diagnosis of odontogenic keratocysts. Int J Oral Surg 1973;2:143-51.

4 Douglas CWI, Craig GT. A search for novel components associ- 윽 ated with odontogenic cyst fluids. J Dent Res 1985;64:666.

5 Douglas CWI, Craig GT. Recognition of a protein apparently $\vec{D}$ specific to odontogenic keratocyst fluids. J Clin Pathol 1986;39:1108-15.

6 Rice RH, Green H. Presence in human epidermal cells of a soluble protein precursor of the cross-linked envelope: activation of $\vec{A}$ the cross-linking by calcium ions. Cell 1979;18:681-94.

7 Coombs RRA, Bedford D, Ronillard, LM. A and B blood-group . antigens on human epidermal cells demonstrated by mixed agglutination. Lancet 1956;i:461-3.

8 Mason DY, Taylor CR. Distribution of transferrin, ferritin and lactoferrin in human tissues. J Clin Pathol 1978;31:316-27.

9 Brandtzaeg P. Transport models for secretory IgA and secretory IgM. Clin Exp Immunol 1981;44:221-32.

10 Steinbuch M, Audran, R. The isolation of IgG from mammalian sera with the aid of caprylic acid. Arch Biochem Biophys $\overrightarrow{\overrightarrow{0}}$ 1969;134:279-84.

11 Weeke B. Rocket immunoelectrophoresis. Scand J Immunol 1973;2(suppl 1):37-46.

12 Russell, RRB. Glucan-binding proteins of Streptococcus mutans serotypic. J Gen Microbiol 1979;112:197-201.

13 Burnette WN. "Western blotting". Electrophoretic transfer of proteins from sodium dodecyl sulphate-polyacrylamide gels to $\overline{0}$ unmodified nitrocellulose and radiographic detection with antibody and radioiodinated protein A. Analy Biochem 1981;112:195-203.

14 Douglas CWI, Russell RRB. The adsorption of human salivary components to strains of the bacterium Streptococcus mutans. 을 Arch Oral Biol 1984;29:751-7.

15 Eckersall PD, Beeley JA. Comparison of crossed immu- $\frac{7}{0}$ noelectrophoresis and crossed immunoelectrofocusing for the investigation of human salivary proteins. Electrophoresis $N$ 1980;1:62-7.

16 Mach J-P. In vitro combination of human and bovine free secre- $N$ tory component with IgA of various species. Nature 1970;228:1278-82.

17 Putnam FW, Low T, Liu V, Huser H, Raff E, Wong FC, Clamp $\mathrm{JR}$. Isolation, properties and structure of human IgA myeloma globulins. In: Mestecky J, Lawton AR, eds. The immunoglobulin A system. Adv Exp Med Biol 1974;45:177-81.

18 Mepham BL, Fraser W, Mitchell BS. Use of proteolytic-enzyme to improve immunoglobulin staining by the PAP technique. Histochem J 1979;11:345-57.

19 Simon M, Green H. Participation of membrane-associated proteins in the formation of the cross-linked envelope of the kera- $\frac{\vec{D}}{\mathbb{D}}$ tinocyte. Cell 1984;36:827-34.

20 Kuhn LC, Kraehenbuhl J-P. Interaction of rabbit secretory com- 
ponent with rabbit IgA dimer. J Biol Chem 1979;254:11066-71.

21 Brandtzaeg P. Human secretory immonoglobulins 3. Immunochemical and physiochemical studies of secretory IgA and free secretory piece. Acta Pathol Microbiol Scand B 1971;79:165-88.

22 Masson PL, Heremans JH, Dive CH. An iron-binding protein common to many external secretions. Clin Chim Acta 1966;14:735-9.

23 Lefell MS, Spitznagel JK. Association of lactoferrin with lysozyme in granules of human polymorphonuclear leukocytes. Infect Immun 1972;6:761-5.

24 Oram JD, Reiter B. Inhibition of bacteria by lactoferrin and other iron-chelating agents. Biochim Biophys Acta 1968;170:351-65.

25 Querinjean P, Masson PL, Heremans JF. Molecular weight, single chain structure and amino acid composition of human lactoferrin. Eur J Biochem 1971;20:420-5.

26 Metz-Boutigue ML, Jollès J, Mazurier J, Schoentgen F, Legrand
D, Spik G, Montrellil J, Jollès P. Human lactotransferrin: amino acid sequence and structural comparisons with other transferrins. Eur J Biochem 1984;145:659-76.

27 Brandtzaeg P. Characteristics of SC-Ig complexes formed in vitro. In: Mestecky J, Lawton AR, eds. The immunoglobulin A system. Adv Exp Med Biol 1974;45:87-97.

28 Heckman AM. Association of lactoferrin with other proteins as demonstrated by changes in electrophoretic mobility. Biochim Biophys Acta 1971;251:380-7.

29 Toller PA. Protein substances in odontogenic cyst fluids. Br Dent $J$ 1970;128:317-22.

Requests for reprints to: Dr CWI Douglas, Department of Oral Pathology, School of Clinical Dentistry, 31 Claremont Crescent, Sheffield S10 2TA, England. 